\title{
Структуры с квантовыми ямами НgTe/CdHgТе для ИК фотоприемников: рост и характеризация
}

\author{
Н.Н. Михайлов ${ }^{1,2)}$, С.А. Дворецкий ${ }^{1,3)}$, Д.Г. Икусов ${ }^{1)}$, В.В. Карпов ${ }^{4)}$, В. Г. Ремесник ${ }^{1)}$, В.А. Швец ${ }^{1,2)}$, \\ Е.В. Сусов ${ }^{4)}$, И.Н. Ужаков ${ }^{1)}$, А.В. Филатов ${ }^{4)}$ \\ ${ }^{1}$ ИФП СО РАН, пр. Лаврентьева, 13, Новосибирск, 630090, \\ ${ }^{2}$ НГУ, ул. Пирогова, 2 Новосибирск, 630090 \\ ${ }^{3}$ НИ ТГУ, пр. Ленина 36, Томск, 634050

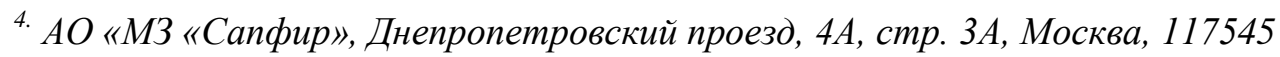 \\ тел:+7 (383) 330-49-67, факс: +7(383) 330-49-67, эл. nочта: mikhailov@isp.nsc.ru
}

DOI 10.34077/RCSP2019-95

Проведено выращивание структур с множественными квантовыми ям (КЯ) НgТе методом молекулярно-лучевой эпитаксии c in situ эллипсометрическим контролем. Представлены спектры поглощения и фотопроводимости, характеристики структур с множественными HgTe КЯ. Измерены спектры поглощения и фотопроводимости. На основе структур с множественными квантовыми ямами $\mathrm{HgTe}$ по заводской технологии были изготовлены ИК фоторезисторы $(50 \times 50$ мкм) и измерены их характеристики.

Рост структур производился на модернезированой установке МЛЭ “Обь-М”. Количество $\mathrm{HgTe} \mathrm{КЯ}$ изменялось от 5 до 200, толщина слоев $\mathrm{HgTe}$ варьировалась от 3 до 18 нм. Состав барьеров $\mathrm{X}_{\mathrm{CdTe}} \geq 0,6 \div 0,75$, толщина барьеров $\mathrm{HgCdTe}$ составляла $\sim 30$ нм. Разработан эллипсометрический метод прецизионного восстановления состава в множественных $\mathrm{HgTe} \mathrm{КЯ,} \mathrm{основанный} \mathrm{на} \mathrm{замене} \mathrm{слоя}$ переменного состава на «эффективную» подложку постоянного состава с эффективными оптическими постоянными. Данный метод позволяет с высокой точностью восстановить

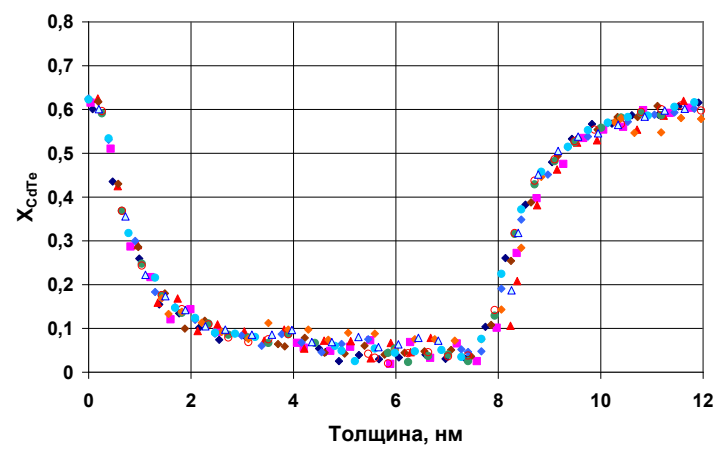

a)

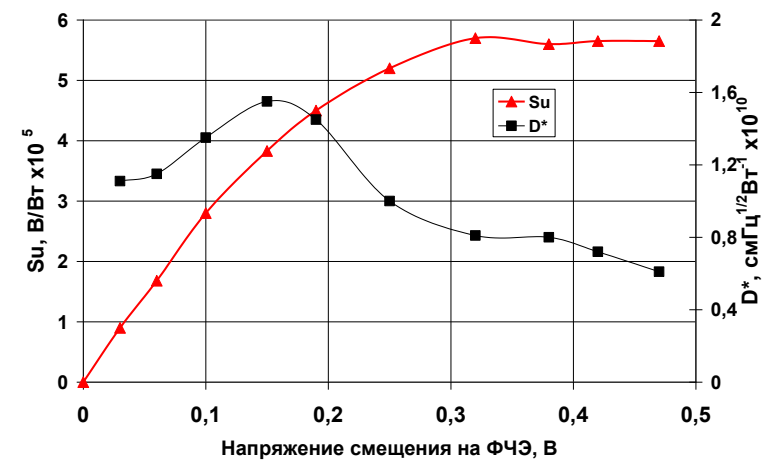

распределение состава по толщине в последовательно выращенных HgТе КЯ На рис.1а представлены типичные профили распределения состава в структуре с $50 \mathrm{HgTe} \mathrm{КЯ.} \mathrm{Видно,} \mathrm{что} \mathrm{в}$ выращенных КЯ наблюдается воспроизводимое изменение распределение состава. Средний статистический разброс для фиксированной координаты составил $\delta \mathrm{X}_{\mathrm{CdTe}} \sim 0,02$ молярных долей.

По заводской технологии АО "МЗ “Сапфир" методом струйного аэрозольного травления на основе MCКЯ HgTe/HgCdTе были изготовлены ИК фоторезисторы, размером $50 \times 50$ мкм без просветляющего покрытия, и измерены их характеристики. Контакты создавались электрохимическим осаждением индия. На рис.1б показана зависимость вольтовой чувствительность $(\mathrm{Su})$ и обнаружительной способности $\left(\mathrm{D}^{*}\right)$ от напряжения смещения. Наблюдается увеличение $\mathrm{Su}$ с выходом на полку при напряжении смещения $\geq 0,25 \mathrm{~B}$, a $\mathrm{D}^{*}$ проходит через максимум при $0,15 \div 0,2 B$. Проведено исследование параметров фоторезисторов при различных фоновых потоках. Значение вольтватной чувствительности составило $5,8 \times 10^{5}$ В/Вт для ИК фоторезисторов с длинноволновой границей $\lambda_{\max }=11,6$ мкм, изготовленных на основе структур с множественными $\mathrm{HgTe}$ КЯ (толщина $\mathrm{HgTe}$ КЯ =8,6 нм, 50 слоев HgTe ).

Работа выполнена при частичной финансовой поддержке РФФИ (проект №18-29-20053) и проекта №0306-2018-0010. 